\title{
Mortality and its Predictors among children on Antiretroviral treatment in Ethiopia: A systematic review and Meta - analysis
}

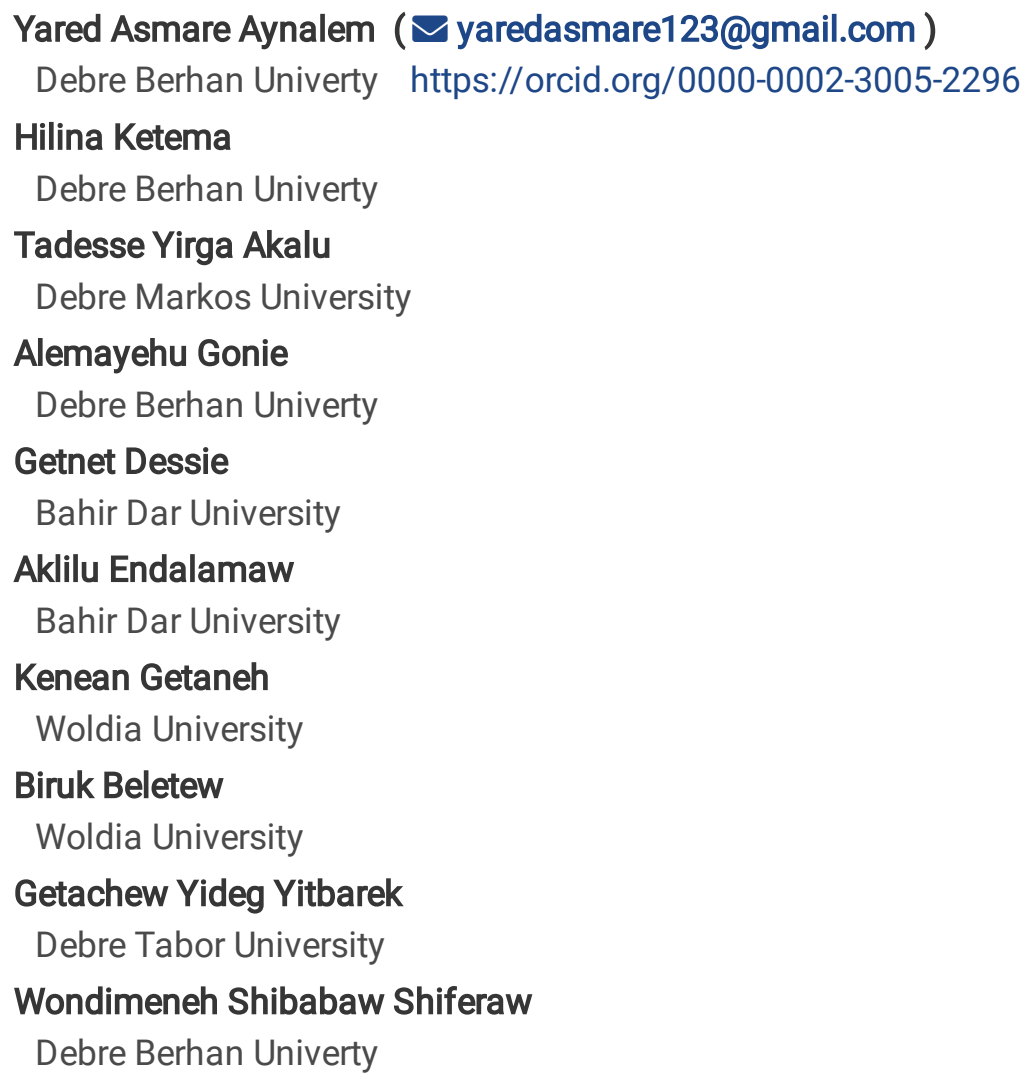




\section{Abstract}

Background: It is well known that antiretroviral therapy (ART) decrease the progress of acquired immune deficiency syndrome (AIDS) related morbidity and mortality and helps the progress towards achieving the United Nations Program on HIV/ AIDS(UNAIDS) treatment goals. Despite this, mortality in Ethiopia becomes public health concern, and variance is observed across studies. With this gap, there is no pooled estimate. Thus, the goal of this study was to assess the pooled mortality and its predictors among antiretroviral treated HIV/AIDS patients.

Methods: PubMed, Scopus and Google Scholar databases were used to search articles. The quality of studies was assessed using the Newcastle Ottawa quality assessment scale. The funnel plot and Egger's test were performed to confirm the presence of publication bias. Heterogeneity across studies was evaluated using the $\mathrm{I}^{2}$ statistic. The pooled incidence rate and its predictors were estimated using a weighted inverse variance random-effects model. Subgroup analysis and sensitivity analysis were also performed.

Results: In this review, 12 studies with the cohort size of 4,935 were included. The overall incidence of mortality rate was 6.02 (95\% Cl: 3.7, 8.2) per 100 person-years. A higher incidence of mortality was observed $(12.51 \%(95 \% \mathrm{Cl}: 0.32,24.7))$ in south nation nationality and Peoples (SNNP) on subgroup analysis. Being advanced world health organization(WHO) clinical stage (AHR:5.34( 95\% Cl: 3.1,9.2.6)), lower CD4 cell count (AHR :2.46 (95\%Cl: 1.8, 3.2)), anemia (AHR :2.76 (95\% Cl: 1.9,3.9)), and nutritional status (AHR :1.9 (95\% Cl: 1.3, 2.6)) were major predictors of mortality. In contrast, cotrimoxazole preventive therapy (CPT) (AHR: 0.34, $(95 \% \mathrm{Cl} 0.05,0.63)$ ) reduced mortality.

Conclusions: In Ethiopia, the incidence of mortality was high. Lower CD4 cell count, anemia, WHO clinical staging (III/IV), and undernutrition were the contributing factors. But cotrimoxazole preventive therapy had a high effect on mortality reduction. Therefore, an earlier management would be started before advancing signs of acquired immune deficiency syndrome (AIDS) regardless of WHO staging, CD4 cell level, and nutritional status.

\section{Background}

The pandemic of Human Immunodeficiency Virus (HIV)/ Acquired immune deficiency syndrome (AIDS) continues to take a tremendous toll on human health, having claimed more than 36.7 million peoples were affected worldwide. Of whom, 1.8 million were children (1). It progresses very rapidly among infants and children. In the absence of Antiretroviral Therapy( ART), $33 \%$ of infants will die before their first birthday, and $50 \%$ will die before the age of two years (2).

Sub-Saharan Africa is the most affected region, with 25.6 million people living with HIV(PLHIV) and accounts for two-thirds of the global total newly infected(1). Near to $91 \%$ of HIV positive children are also in this region (3). HIV /AIDS) remains the foremost reason for death in children (4).

Highly Active Antiretroviral Therapy (HAART) increases the survival and quality of life of people living with HIV/ AIDS (5). It is targeted to improve the immune system and maximize durable suppression of viral reproduction, restoring immunologic function, reduction of HIV/AIDS-related illness and death, improving the quality of life, and extending survival(1).

The World Health Organization (WHO) targeted to reach 15 million ART users by the end of 2015 and reached ahead of schedule. Nevertheless, still, 20 million HIV positive were not able to access ART (6). Moreover, access to ART is still low for children (7). Different studies conducted in developed $(8,9)$ and developing countries showed that inconsistency and increase mortality in children despite the availability of ART $(10,11)$.

Ethiopia is categorized among one of the sub-Saharan countries with the highest HIV/ADIS burden, with about 1.1 million were infected with 14,405 new infections per year. From this, approximately 109,133 were Children's which accounts for 2,420 of the newly infected(12). The government launched fee-based ART in 2003 and free-based in 2005, delivered as part 
of the comprehensive HIV/AIDS care (13). Despite the rapid scale-up of children ART coverage, it is still very low in Ethiopia (14).

Multi-factorial causes contribute to increasing the burden of mortality in antiretroviral treated HIV/AIDS -Positive children. However, some major risk factors include low hemoglobin count $(<10 \mathrm{~g} / \mathrm{dl})(5,15)$, low CD 4 count or \% below the threshold level (5), WHO clinical stage(III\&IV) $(5,15)$, poor adherence to ART (16), and severe wasting (17). In our country, several single institution-based studies have been conducted in different regions. But, the incidence of mortality varied largely across studies which range from $4.02 \%$ (18)to $22.9 \%(19)$.

The level of mortality among children on ART in Ethiopia represented with high inconsistency and variable figures. For instance a study in Amhara region for example showed that the proportion of mortality ranges from 7.7-22.9\% (18-20) and $10-15.5 \%$ in SNNPR region(21-23). with this discrepancy there is no any pooled result. Therefore, this study aimed to estimate the pooled incidence of mortality and its predictors in antiretroviral treated HIV/AIDS -positive children in Ethiopia. Therefore, this study aimed to estimate the pooled incidence of mortality and its predictors in antiretroviral treated HIV/AIDS -positive children in Ethiopia.

\section{Methods}

\section{Literature search strategy}

PubMed, Google Scholar, Scopus, and Web of Science databases were used to get the articles. Grey literature, such as unpublished articles and conference abstracts, were assessed. Endnote X 8.1 reference manager software was used to gather the searched articles and for the removal of duplicate articles. The search was conducted using the following terms and phrases: "Human Immunodeficiency virus", "Acquired Immunodeficiency syndrome”, "antiretroviral therapy", "AIDS", the incidence of mortality "HIV", "predictors", "determinates" "children” and "Ethiopia”. The searching date in PubMed through search terms was 26/04/2020. The search strategy made in PubMed was: (((("epidemiology"[Subheading] OR "epidemiology"[All Fields] OR "incidence"[All Fields] OR "incidence"[MeSH Terms]) AND ("mortality"[Subheading] OR "mortality"[All Fields] OR "mortality"[MeSH Terms])) AND Predictors[All Fields]) AND (("anti-retroviral agents"[All Fields] OR "anti-retroviral agents"[MeSH Terms] OR ("anti-retroviral"[All Fields] AND "agents"[All Fields]) OR "anti-retroviral agents"[All Fields] OR "antiretroviral"[All Fields]) AND treated[All Fields] AND ("acquired immunodeficiency syndrome"[MeSH Terms] OR ("acquired"[All Fields] AND "immunodeficiency"[All Fields] AND "syndrome"[All Fields]) OR "acquired immunodeficiency syndrome"[All Fields] OR "hiv aids"[All Fields]) AND -Positive[All Fields])) AND ("child"[MeSH Terms] OR "child"[All Fields] OR "children"[All Fields])) AND ("ethiopia"[MeSH Terms] OR "ethiopia"[All Fields]) Additionally, articles were searched from Addis Ababa University electronic repository system.

\section{Inclusion and exclusion criteria}

Articles were included if they fulfill the following standards: (1) HIV/AIDS infected children whose age is below 15 years old and on ART. (2) Observational studies like cohort, case-control, and cross-sectional studies, (3) studies that report the incidence rate, prevalence and/ or HR (hazard ratio), OR (odds ratio) of Predictors in Antiretroviral treated HIV/AIDS -Positive children, (4) studies done in Ethiopia, and [4] studies published in English language. Studies that didn't report the incidence/prevalence and/or determinants of mortality. Studies conducted on adult HIV infected patients or included both adults and Studies that will not provide full information/ missed data were excluded.

Studies conducted on adult HIV infected patients or included both adults and children and Studies that will not provide full information/ missed data were excluded.

\section{Outcome measurement}


The primary outcome is the level of mortality and the secondary outcome is major predictors in Antiretroviral treated HIV/AIDS -positive children.

\section{Operational definitions}

Incidence of mortality: The rate of child death during the follow-up period to the total person-years of observation.

WHO clinical stage: categorized as exposed when they are in advanced WHO clinical staging (stage three and four) and non-exposed (stage one and two)

Low CD4 count: it was classified based on the child's age (for Infants CD4<1500/mm3, 12-35 months $<750 / \mathrm{mm} 3,36-59$ months $<350 / \mathrm{mm}^{2}$ and $\geq 5$ years $<200 / \mathrm{mm}^{3}(24)$

Anemia: was defined and graded according to age-appropriate reference standards published by WHO (25) and the report of included studies(Anemia was defined as having hemoglobin level of less than $10 \mathrm{mg} / \mathrm{dl}$.

Nutritional status: malnourished / undernutrition was defined as weight for age Z-score < -2 SD for under-five children and BMI for age Z-score < -2 SD for older children

\section{Methods for Data Extraction and Quality Assessment.}

We used a Microsoft excel form to extract data. The following information was extracted for each incorporated finding: the name of the first author, publication year, country, region, study design, associated factors, sample size, final included, response rate, study settings, risk estimate (HR), incidence rate and the $95 \%$ confidence interval. Data extraction from source documents was done independently by all investigators. Disagreements were resolved by consensus. The quality of the included studies was evaluated using the Newcastle-Ottawa Scale (NOS) (26). The criteria for cohort studies were selection graded by six stars, comparability graded by two stars, and outcome graded by five stars. Cohort studies scored 9 and/or above quality assessment criteria were included.

\section{Data synthesis and statistical analysis}

STATA 14 statistical software was used for analysis. Publication bias was assessed by the funnel plot and Egger's regression test. $\mathrm{I}^{2}$ statistics were used to check the heterogeneity of studies. The DerSimonianLaird random-effects model was done to estimate the overall level. Subgroup analysis based on the region of the studies was conducted. Sensitivity analysis was also conducted to see the effect of a single study on the overall effect estimation.

\section{Results}

\section{Explanation for original studies}

A total of 473 articles were retrieved from PubMed $(n=186)$, Google Scholar $(n=244)$, Web of Science $(n=8)$, Scopus $(n=18)$, and Addis Ababa University's' online source library $(n=1)$ and 16 in other sources. A total of 326 articles have remained after duplicate studies were removed. Of which, 126 were rejected just by reading only the titles. Of the remaining 90 studies, 51 were excluded after reading their abstracts. Full text copies of the remaining 39 studies that potentially fulfilled the inclusion criteria were assessed. After further screening, 12 papers were retained for inclusion, and all were published in the English language. Based on the predefined criteria and quality assessment, only 12 articles were included for the final analysis (Figure1).

\section{Characteristics of the included studies}

In this systematic review and meta-analysis, 12 studies with the cohort size of 4,935 pediatric patients on ART were included. Searches from the databases were done between 2012 and 2018. All of the studies which were included in this review had a 
cohort study design. Three of the studies were conducted in the Amhara region(18-20) and the other three of the studies were conducted in SNNPR region(21-23), while two in Addis Ababa $(16,27)$ and Oromia(28, 29), one in Tigray $(30)$ and one in Harari(31). The sample size of the studies ranging from 96 (28) to 757(27)(table 1).

Table 1: Characteristics of the included studies

\begin{tabular}{|c|c|c|c|c|c|c|}
\hline ar & Area & Region & Total sample & Incidence of mortality & $\begin{array}{c}\text { Response } \\
\text { Rate }\end{array}$ & Media follow up \\
\hline st $\mathrm{al} / 2015$ & Harer & Harari & 305 & 3.8 & 100 & 30 \\
\hline /2012 & Bahir Dar & Amhara & 579 & 4 & 94.81 & 22 \\
\hline thin et al./2013 & Mekelle & Tigray & 432 & 1.4 & 96.3 & 36 \\
\hline I. et al/2009 & Jimma & Oromia & 96 & 2.1 & 100 & 24 \\
\hline l. $/ 2018$ & Debre Tabor & Amhara & 462 & 5.2 & 92.2 & 44 \\
\hline al./2018 & Arba Minch & SNNP & 421 & 15.3 & 100 & 41 \\
\hline L./2014 & Adama & Oromia & 560 & 2.06 & 100 & 47 \\
\hline / 2017 & Addis Ababa & Addis Ababa & 757 & 12.4 & 100 & 9 \\
\hline ət al./2015 & Addis Ababa & Addis Ababa & 556 & 3.5 & 100 & - \\
\hline tt al./2016 & Jinka & SNNP & 350 & 1.75 & 100 & - \\
\hline l./2017 & Wolaita & SNNP & 260 & 21.02 & 87.6 & - \\
\hline 12018 & Gondar & Amhara & 271 & 3.27 & 100 & 4 \\
\hline
\end{tabular}

\section{Publication bias and heterogeneity}

The presence of heterogeneity and publication bias was evaluated within included studies. Subsequently, there was no any significant heterogeneity across the included studies in this meta-analysis $\left(\mathrm{I}^{2}=44.2 \%\right)$. We found that there was publication bias among the included studies, as depicted by the asymmetrical distribution of our funnel plot (Figure 2). Likewise, the result of Egger's test was statistically significant for the presence of publication bias $(P=0.004)$. To reduce and adjust publication bias, trim and fill analysis was also performed(figure 4).

\section{Mortality among children on Antiretroviral treatment}

The current meta-analysis using the random-effects model showed that the estimated overall incidence of mortality in antiretroviral treated HIV/AIDS -Positive Children was 6.02 (95\% Cl: 3.7, 8.2) per 100 person-years of observation with the low level of heterogeneity $\left(\mathrm{I}^{2}=44.2 \%, \mathrm{p}=0.64 \%\right)$ (Figure 3$)$.

A total of $9.2 \%(95 \% \mathrm{Cl}: 6.8,11.53)$ was died during the follow-up time (Table 2$)$.

Table 2: the proportion of mortality in antiretroviral treated HIV/AIDS -Positive Children 


\begin{tabular}{|l|l|l|}
\hline Author/year & Proportion (95\% CI) & Weight (\%) \\
\hline Dumessa et al (2015) & $9.2(5.9,12.4)$ & 8.15 \\
\hline Koye et al (2012) & $7.5(5.3,9.7)$ & 8.90 \\
\hline Gebremedhin et al. (2013) & $4.81(2.75,6.8)$ & 9.0 \\
\hline etsanet W. et al (2009) & $7.3(2.1,12.5)$ & 6.53 \\
\hline Arage et al. (2018) & $22.9(18.9,26.9)$ & 7.54 \\
\hline Sidamo et al. (2018) & $15.4(11.9,18.8)$ & 7.9 \\
\hline Kedir et al., (2014) & $7.6(5.4,9.8)$ & 8.91 \\
\hline Dube et al. (2017) & $6.7(4.9,8.5)$ & 9.2 \\
\hline G. Ebissa et al. (20 15 & $10.4(7.9,12.9)$ & 8.7 \\
\hline Tachbele et al. (2016) & $10(6.9,13.1)$ & 8.2 \\
\hline Bitew et al. (2017) & $6.8(3.5,10.1)$ & 8.13 \\
\hline Atalel et al. (2018) & $4.02(1.7,6.4)$ & 8.8 \\
\hline Pooled estimate & $9.2(6.8,11.53)$ & 9.2 \\
\hline
\end{tabular}

\section{Subgroup analysis}

Subgroup analysis was employed based on region and sample size of the study participants, study design. A higher incidence of HIV/AIDS-related mortality was $12.51 \%$ in SNNP $(95 \% \mathrm{Cl}: 0.32,24.7)$. But there is no ay difference in mortality with sample size (Table 3).

Table 3: Subgroup analysis with the region and sample size of the study participants

\begin{tabular}{|c|c|c|c|c|c|}
\hline Subgroup analysis & Category & The pooled incidence of mortality $(95 \% \mathrm{CI})$ & $\%$ Weight & p-value & $\begin{array}{l}\text { Heterogeneity } \\
\left(\mathrm{I}^{2}\right)\end{array}$ \\
\hline \multirow[t]{2}{*}{ Sample size } & $<400$ & $5.54(1.91,9.17)$ & 39.78 & 0.32 & 38 \\
\hline & $>400$ & $5.99(3.18,8.82)$ & 60.22 & 0.64 & 5.39 \\
\hline \multirow[t]{6}{*}{ Region } & Addis Ababa & $7.9(0.81,16.6)$ & 17.25 & 0.34 & 67.8 \\
\hline & Amhara & $4.131(3.03,5.23$ & 25.9 & 0.439 & 0.0 \\
\hline & SNNP & $12.51(0.32,24.7)$ & 22.28 & 0.61 & 65.1 \\
\hline & Oromia & $2.16(0.97,3.15)$ & 17.01 & 0.98 & 97 \\
\hline & Tigray & $1.4(0.27,2.5)$ & 9.1 & 0.00 & - \\
\hline & Hareri & $3.8(1.65,5.9$ & 8.5 & 0.001 & - \\
\hline
\end{tabular}

\section{Meta-regression}

To examine the likely causes of disparity across studies, we conduct meta-regression ana-lysis using publication year and sample size. But the result showed there is no any significant heterogeneity (Table 4).

Table 4: Meta-regression results of the included studies.

\begin{tabular}{|l|l|l|l|l|l|}
\hline & Coefficient & Standard error & $\mathrm{T}$ & P-value & $95 \% \mathrm{CI}$ \\
\hline Publication year & 1.19. & 0.68 & 1.74 & 0.12 & $0.35,2.73$ \\
\hline Total sample size & 0.001 & 0.011 & 0.17 & 0.87 & $0.02 \quad 0.02$ \\
\hline
\end{tabular}


Trim ad fill(figure 4)

\section{Sensitivity analysis}

Sensitivity analysis indicated that the impact of each findings on pooled estimate was insignificant, telling the robustness of aggregated estimate. Hence, the pooled mortality among HIV infected children on ART was constant and unaffected when assessed by removing one study at a time which implies no any single study significantly affect the pooled mortality result of the current meta-analysis (figure 5).

\section{Predictors of Mortalities}

\section{WHO clinical staging}

In this review pooled effect of six studies showed being on WHO clinical stage III/ IV found to be at higher risk (AHR=5.346; $95 \% \mathrm{Cl}: 3.1-9.2 .6)$ to death as compared to stage II/I. Having a Progressive WHO staging (stage III and IV) at the baseline was 5.36 times more likely to die than the WHO clinical stage I and II(figure 6).

\section{Baseline CD4 Cells count}

Baseline CD4 Cells count was also another contributing factor to the incidence of mortality in antiretroviral treated HIV/AIDS -positive children. The pooled hazard ratio of patients with low CD4 cell count at the initiation of HAART was 2.46 (95\%Cl: 1.8, 3.2) (figure 7).

\section{Opportunistic infection}

The association between Opportunistic infection and the incidence of mortality was reported in four articles. The current meta-analysis showed that the likelihood of death among HIV/AIDS patients with opportunistic infection at the baseline was $3.43(95 \% \mathrm{Cl}: 1.08,10.8)($ figure 8$)$.

\section{Anemia}

The pooled hazard ratio of children in antiretroviral treated HIV/AIDS patients with low hemoglobin levels at initiation of HAART was 2.76 (95\% Cl: 1.9-3.9). The pooled hazard ratio of children diagnosed with anemia had 2.76 times the risk of death compared to its counterpart (Figure 9).

\section{Nutritional status}

Having Malnutrition were factors significantly associated with mortality in antiretroviral treated HIV/AIDS -Positive children mortality. Those malnourished children at the baseline were $1.9(95 \% \mathrm{Cl}: 1.3,2.6)$ times more likely to die (figure 10).

\section{Cotrimoxazole Preventive Therapy (CPT)}

Based on the current meta-analysis, those receiving iron therapy were $66 \%$ less likely to die as compared to those who had not taken CPT (AHR: 0.34, 95\% Cl 0.05, 0.63). (figure 11).

\section{Discussion}

Assessing the effectiveness of ART in delaying disease advancement and reducing mortality in children deserves an urgent and wide-scale, evidence-based assessment(32). The cumulative incidence of death at different periods was not consistently reported by all the studies in Ethiopia. Therefore, the current systematic review and meta-analyses were aimed to synthesize the incidence of mortality and its predictors in antiretroviral treated HIV/AIDS -positive children. Based on the results of this review, the pooled incidence of mortality was 6.02 (95\% Cl: 3.7, 8.2) per 100 person-years of observation. There are very few 
similar reviews comparable with our findings of pooled mortality estimates (33). Nevertheless, the current finding is higher than a study done in Malawi, Lesotho, and Swaziland(34) and Kinshasa, Democratic Republic of Congo(35).

This discrepancy might be due to the difference in the study period as there could be changes in the treatment and care modality of children on ART through time and a variation in ART enrollment time where the previous finding addressed children who started ART in earlier years with different treatment eligibility standard in which the WHO has made significant changes in ART initiation for pediatric irrespective of clinical or immunologic status(36, 37).

Additionally, it could be due to delayed ART initiation which increases the risk of advancing clinical staging, immune reconstitution inflammatory Syndrome, severe malnutrition, opportunistic infection, and drug toxicity and This difference could be due to a variation in ART enrollment periods where the previous studies addressed children who started ART in earlier years with different treatment eligibility criteria in which the WHO has made significant changes in the recommended pediatric age for ART initiation, regardless of clinical or immunologic status(36, 37).

Several multifaceted factors contribute to the uneven effect of pediatric HIV/ADIS in developing nations like stigmatization, cultural and social challenges to testing and treatment, inadequate health care set-up to support the patient, scarcity of trained health manpower in the field, scarcity of medical equipment and small qualified laboratory services(38). In Ethiopia, the cumulative pooled proportion of deaths was $9.2 \%(95 \% \mathrm{Cl}: 6.8,11.53)$. This result is consistent with the mortality rate reported in systematic review and meta-analysis (39) and a study in resource-limited countries (35). In contrast, a lower proportion of death was reported in the following studies $(34,40,41)$.

As can be noted from the findings of this systematic review and meta-analysis, the predominant risk factors of mortality were being on the WHO clinical stage III/IV, lower CD4 cell count, and occurrence of opportunistic infections, anemia, and nutritional status. However, CPT was found to be preventive predictors.

The current study revealed that having a progressive WHO staging (stage III and IV) found to have a great impact on the occurrence of HIV/ADIs related to death. Those with progressive WHO staging (stage III and IV) were five-point three times more likely to die. This finding is congruent with previous studies conducted in different countries $(33,34)$ and Sub-Saharan Africa $(39,40)$.

The result of different studies revealed that lower CD4 cell count were the predominant predictors of mortalities $(33,35,40)$. As CD4 count gets decline, the immune system of HIV/AIDS positive children would be very weak and leads to an increased vulnerability of $\mathrm{OI}$, the most important case of child morbidities and mortalities(42). As evidenced by this study, baseline CD4 Cells count below the threshold for severe immunodeficiency was also another contributing factor for the incidence of mortality. This result was also supported by several studies $(33,35,40)$. This

The presence of the opportunistic infection has also found to be a higher risk of death. Similar findings were reported in other studies conducted in Asia (43). As the patient started HAART in a more advanced stage and lower CD4 count, the risk of developing immune reconstitution syndrome and OI would be higher, which leads to an increase in the rate of viral replication(44).

The pooled hazard ratio with lower hemoglobin level (below $10 \mathrm{gm} / \mathrm{dl}$ ) at the initiation of ART was also higher as compared to its counterpart which was supported by studies from a study done in Sub-Saharan Africa (39). Hematological complications such as Zidovudine(ZDV) associated anemia are among the commonly reported adverse drug reactions of Antiretroviral Therapy(ART).

In our study, the incidence of death was significantly lower in children who were well-nourished than in those who were undernourished at baseline This finding is in line with other studies conducted in resource-deprived settings(35) and a study done in Kenya (33). The current meta-analysis revealed that patients who have taken CPT were $66 \%$ times less likely to die as compared to those who had not taken which in lines with the WHO guidelines which promote CPT implemented as an 
integral component of a package of HIV-related services which prevent most of the opportunistic infections including tuberculosis which may reduce the rate of death $(45,46)$. Strengths and limitations of the study: As far as we know this is the first meta-analysis that has been done in Ethiopia. All of the included studies were with high methodological quality based on NOS assessment and similar study design. Despite this, our study had the following limitations. Like other meta-analyses, this study has several limitations that must be careful before interpreting results. the studies used for this analysis are not addressed all region of Ethiopia due to limited studies. Therefore, this could have a significant effect on inferring the finding.

\section{Conclusion}

This study noted that there was a high rate of mortality. Advanced WHO clinical staging (III/IV), lower CD4 cell count, presence of opportunistic infections, anemia, and undernutrition were factors associated with mortality in antiretroviral treated HIV/AIDS -Positive. In contrast, CPT was found to have a protective effect. Therefore, the health care provider and government need to emphasis on tedious screening of antiretroviral treated HIV/AIDS -positive children with low hemoglobin levels, advanced WHO clinical staging (III/IV), lower CD4 cell count, presence of opportunistic infections. Furthermore, CPT should be initiated as early as possible to all children regardless of clinical or immunologic status to reduce the incidence of childhood morbidity and mortality. Additionally, HIV infected children need frequent monitoring of growth and development, to detect growth faltering and developmental abnormalities early enough ad nutritional diversification shall be enhanced.

\section{Declarations}

\section{Acknowledgements}

Not applicable.

\section{Authors' contributions}

YA: Conceived and designed the study, reviewed literatures, extracted and analyzed data, interpreted results and drafted the manuscript. WS, TY, GD, AE, KG, BB ,HK, GY and AG involved in study selection, data collection, extraction, quality assessment and reviewing the manuscript. All the authors participate in supervision, analysis and interpretation, reviewed the manuscript thoroughly for its scientific content. All authors have read and approved the manuscript.

\section{Funding}

None.

\section{Availability of data and materials}

All data pertaining to this study are contained and presented in this manuscript.

\section{Ethics approval and consent to participate}

Not applicable.

\section{Consent for publication}

Not applicable.

\section{Competing interests}

The authors declare that they have no competing interests.

\section{References}


1. UNAIDS. Global AIDS update Geneva Switzerland available from

http://www.unaids.org/sites/default/files/media_asset/global-AIDS-update-2016_en.pdf. access date december 27,2016. 2016. p. p3.

2. UNICEF. United Nations Children's Fund,Towards an AIDS-Free Generation - Children and AIDS: Sixth Stocktaking Report, available from www.unaids.org/sites/.../20131129_stocktaking_report_children_aids_en_0.pdf. 2013.

3. UNAIDS. Fact sheet. available from

http://www.unaids.org/en/media/unaids/contentassets/documents/factsheet/2014/20140716_FactSheet_en.pdf2014. p. 1-6.

4. UNICEF. UNICEF ANNUAL REPORT available from https://www.unicef.org/publications/files/UNICEF_Annual_Report_2015_En.pdf. 2015.

5. Koye DN, Ayele TA, Zeleke BM. Predictors of mortality among children on Antiretroviral Therapy at a referral hospital, Northwest Ethiopia: a retrospective follow up study. BMC Pediatr. 2012;12:161.

6. UNAIDS. the AIDS epidemic canbe ended by 2030 with your help available from http://www.unaids.org/sites/default/files/media_asset/UNAIDS_with-your-help_en.pdf. 2016.

7. HIV/AIDS JUNPo. Access to antiretroviral therapy in Africa: status report on progress towards the 2015 targets. Geneva, Switzerland: Joint United Nations Programme on HIV. AIDS. 2013:1-12.

8. Luque MT, Jenkins CA, Shepherd BE, Padgett D, Rouzier V, Succi RC, et al. Mortality in Children with Human Immunodeficiency Virus Initiating Treatment: A Six-Cohort Study in Latin America. J Pediatr. 2017.

9. Moreira-Silva SF, Zandonade E, Miranda AE. Mortality in children and adolescents vertically infected by HIV receiving care at a referral hospital in Vitoria, Brazil. BMC Infect Dis. 2015;15:155.

10. Mwiru RS, Spiegelman D, Duggan C, Seage GR, 3rd, Semu H, Chalamilla G, et al. Nutritional Status and Other Baseline Predictors of Mortality among HIV-Infected Children Initiating Antiretroviral Therapy in Tanzania. Journal of the International Association of Providers of AIDS Care. 2015;14(2):172-9.

11. Wamalwa DC, Obimbo EM, Farquhar C, Richardson BA, Mbori-Ngacha DA, Inwani I, et al. Predictors of mortality in HIV-1 infected children on antiretroviral therapy in Kenya: a prospective cohort. BMC Pediatr. 2010;10:33.

12. NationaIAIDSResourceCenter. HIV/AIDS Estimates and Projections in Ethiopia, 2011-2016 available from http://fitun.etharc.org/resources/finish/53-hiv-aids-estimates-and-projections/327-hiv-aids-estimates-and-projections-inethiopia-2011-2016. 2011.

13. FMOH. National Comprehensive HIV Care and Treatment Training for Health care Providers unpublished report. June, 2014.

14. UNAIDS. Etiopia HIV Epidemic available from http://www.unaidsrstesa.org/wp-content/uploads/2015/05/UNAidsProfile-Ethiopia.pdf 2014.

15. Gebremedhin A, Gebremariam S, Haile F, Weldearegawi B, Decotelli C. Predictors of mortality among HIV infected children on anti-retroviral therapy in Mekelle Hospital, Northern Ethiopia: a retrospective cohort study. BMC Public Health. 2013;13:1047.

16. Ebissa G, Deyessa N, Biadgilign S. Predictors of early mortality in a cohort of HIV-infected children receiving high active antiretroviral treatment in public hospitals in Ethiopia. AIDS care. 2015;27(6):723-30.

17. Shimelash B. Assessment of the effect of malnutrition on survival of HIV infected children after initiation of antiretroviral treatment in Wolaita zone health facilities, SNNPR, Ethiopia: AAU; 2014.

18. Atalell KA, Tebeje NB, Ekubagewargies DT. Survival and predictors of mortality among children co-infected with tuberculosis and human immunodeficiency virus at University of Gondar Comprehensive Specialized Hospital, Northwest Ethiopia. A retrospective follow-up study. PloS one. 2018;13(5).

19. Arage G, Assefa M, Worku T, Semahegn A. Survival rate of HIV-infected children after initiation of the antiretroviral therapy and its predictors in Ethiopia: A facility-based retrospective cohort. SAGE open medicine.

Page $10 / 23$ 
2019;7:2050312119838957.

20. Koye DN, Ayele TA, Zeleke BM. Predictors of mortality among children on Antiretroviral Therapy at a referral hospital, Northwest Ethiopia: a retrospective follow up study. BMC pediatrics. 2012;12(1):161.

21. Bitew S, Mekonen A, Assegid M. Predictors on mortality of human immunodeficiency virus infected children after initiation of antiretroviral treatment in Wolaita zone health facilities, Ethiopia: retrospective cohort study. J AIDS HIV Res. 2017;9(4):89-97.

22. Sidamo NB, Hebo SH. Survival time and its predictors among HIV-infected children after antiretroviral therapy in public health facilities of Arba Minch town, Gamo Gofa Zone, Southern Ethiopia. Ethiopian Journal of Health Development. 2018;32(2).

23. Tachbele E, Ameni G. Survival and predictors of mortality among human immunodeficiency virus patients on antiretroviral treatment at Jinka Hospital, South Omo, Ethiopia: a six years retrospective cohort study. Epidemiology and health. 2016;38.

24. Yismaw AE, Gelagay AA, Sisay MM. Survival and predictors among preterm neonates admitted at University of Gondar comprehensive specialized hospital neonatal intensive care unit, Northwest Ethiopia. Italian journal of pediatrics. 2019;45(1):4.

25. Organization WH. Haemoglobin concentrations for the diagnosis of anaemia and assessment of severity. World Health Organization, 2011.

26. Sathenahalli V, Dwivedi D, Bajaj N, Singh H. Predictors of poor outcome in neonates with respiratory distress. Int J Contemp Pediatr. 2016;3:76-9.

27. Mulugeta A, Assefa H, Tewelde T, Dube L. Determinants of survival among HIV positive children on antiretroviral therapy in public hospitals, Addis Ababa, Ethiopia. Qual Prim Care. 2017;25(4):235-41.

28. Workneh N, Girma T, Woldie M. Immunologic and clinical outcomes of children on HAART: a Retrospective cohort analysis at Jimma University specialized hospital. Ethiopian Journal of Health Sciences. 2009;19(2).

29. Kedir A, Desta A, Fesseha G. Factors affecting survival of HIV positive children taking antiretroviral therapy at Adama Referral Hospital and Medical College, Ethiopia. J AIDS Clin Res. 2014;5(3):1-6.

30. Gebremedhin A, Gebremariam S, Haile F, Weldearegawi B, Decotelli C. Predictors of mortality among HIV infected children on anti-retroviral therapy in Mekelle Hospital, Northern Ethiopia: a retrospective cohort study. BMC public health. 2013;13(1):1047.

31. Edessa D, Asefa F, Sheikahmed J. Early mortality among HIV-positive children initiated anti-retroviral therapy in eastern Ethiopia: a retrospective cohort study. Science, Technology and Arts Research Journal. 2015;4(2):157-63.

32. Arrivé E, Kyabayinze DJ, Marquis B, Tumwesigye N, Kieffer M-P, Azondekon A, et al. Cohort profile: the paediatric antiretroviral treatment programmes in lower-income countries (KIDS-ART-LINC) collaboration. International Journal of Epidemiology. 2008;37(3):474-80.

33. Wamalwa DC, Obimbo EM, Farquhar C, Richardson BA, Mbori-Ngacha DA, Inwani I, et al. Predictors of mortality in HIV-1 infected children on antiretroviral therapy in Kenya: a prospective cohort. BMC pediatrics. 2010;10(1):33.

34. Study HPPMC. Use of total lymphocyte count for informing when to start antiretroviral therapy in HIV-infected children: a meta-analysis of longitudinal data. The Lancet. 2005;366(9500):1868-74.

35. Nugent J, Edmonds A, Lusiama J, Thompson D, Behets F, Care PH, et al. Predicting mortality in HIV-infected children initiating highly active antiretroviral therapy in a resource-deprived setting. The Pediatric infectious disease journal. 2014;33(11):1148-55.

36. Ditekemena J, Luhata C, Bonane W, Kiumbu M, Tshefu A, Colebunders R, et al. Antiretroviral treatment program retention among HIV-infected children in the Democratic Republic of Congo. PLoS One. 2014;9(12).

37. Davies N, Heffron R. Global and national guidance for the use of pre-exposure prophylaxis during peri-conception, pregnancy and breastfeeding. Sexual health. 2018;15(6):501-12.

Page $11 / 23$ 
38. Berhe T, Melkamu Y, Amare A. The pattern and predictors of mortality of HIV/AIDS patients with neurologic manifestation in Ethiopia: a retrospective study. AIDS research and therapy. 2012;9(1):11.

39. Collaboration K-A-L. Low risk of death, but substantial program attrition, in pediatric HIV treatment cohorts in SubSaharan Africa. JAIDS Journal of Acquired Immune Deficiency Syndromes. 2008;49(5):523-31.

40. Fenner L, Brinkhof MW, Keiser O, Weigel R, Cornell M, Moultrie H, et al. Early mortality and loss to follow-up in HIVinfected children starting antiretroviral therapy in Southern Africa. Journal of acquired immune deficiency syndromes (1999). 2010;54(5):524.

41. Penazzato M, Davies M-A, Apollo T, Negussie E, Ford N. Task shifting for the delivery of pediatric antiretroviral treatment: a systematic review. JAIDS Journal of Acquired Immune Deficiency Syndromes. 2014;65(4):414-22.

42. Kupka R, Msamanga GI, Aboud S, Manji KP, Duggan C, Fawzi WW. Patterns and predictors of CD4 T-cell counts among children born to HIV-infected women in Tanzania. Journal of tropical pediatrics. 2009;55(5):290-6.

43. Prasitsuebsai W, Kariminia A, Puthanakit T, Lumbiganon P, Hansudewechakul R, Moy FS, et al. Impact of antiretroviral therapy on opportunistic infections of HIV-infected children in the TREAT Asia pediatric HIV observational database. The Pediatric infectious disease journal. 2014;33(7):747.

44. Okoye AA, Picker LJ. CD 4+ T-cell depletion in HIV infection: mechanisms of immunological failure. Immunological reviews. 2013;254(1):54-64.

45. Homsy J, Dorsey G, Arinaitwe E, Wanzira H, Kakuru A, Bigira V, et al. Protective efficacy of prolonged co-trimoxazole prophylaxis in HIV-exposed children up to age 4 years for the prevention of malaria in Uganda: a randomised controlled open-label trial. The Lancet Global health. 2014;2(12):e727-e36.

46. Organization WH. Guidelines for an integrated approach to the nutritional care of HIV-infected children (6 months-14 years). 2009.

\section{Figures}




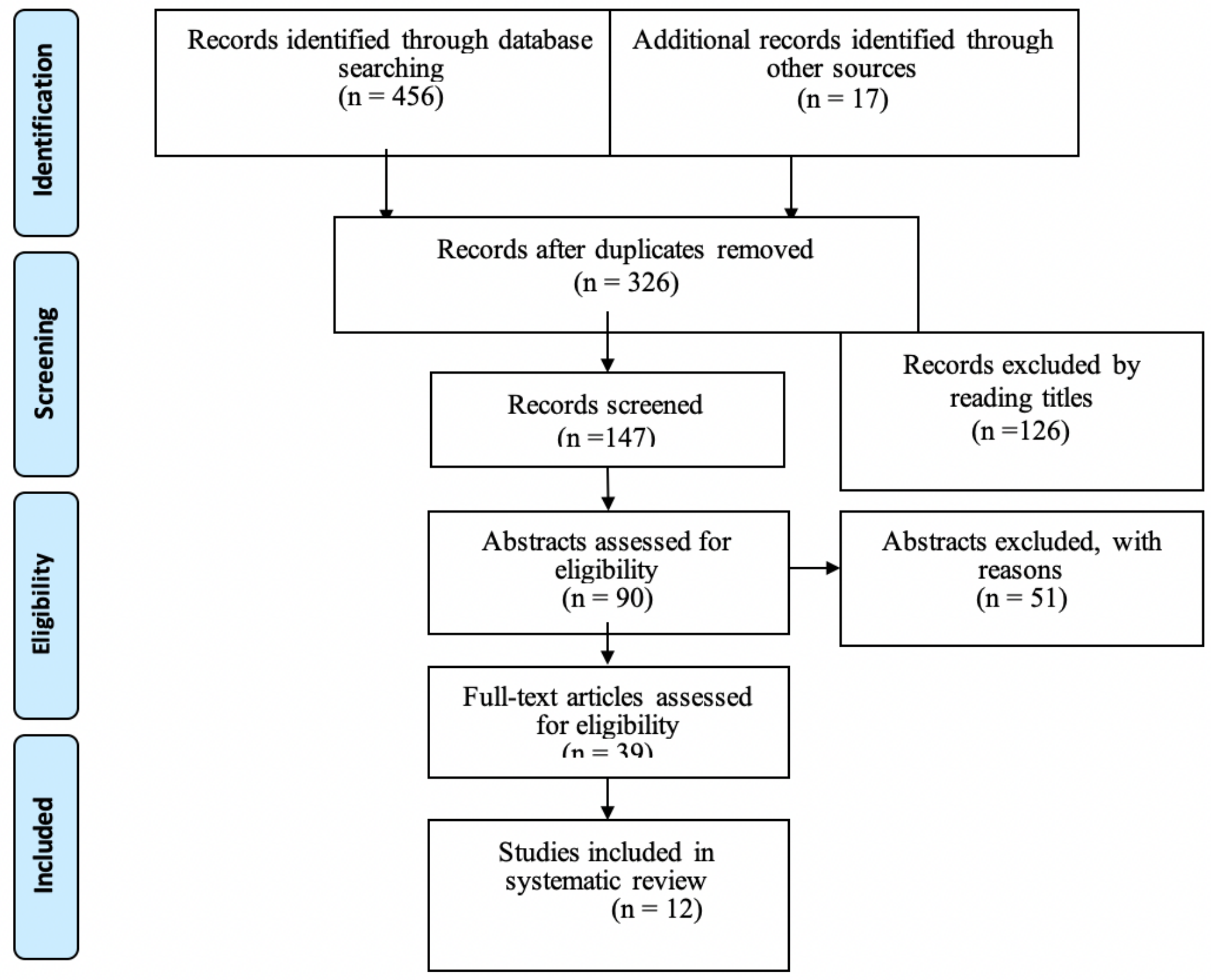

Figure 1

Flow chart showing how the research articles were searched 
Funnel plot with pseudo $95 \%$ confidence limits

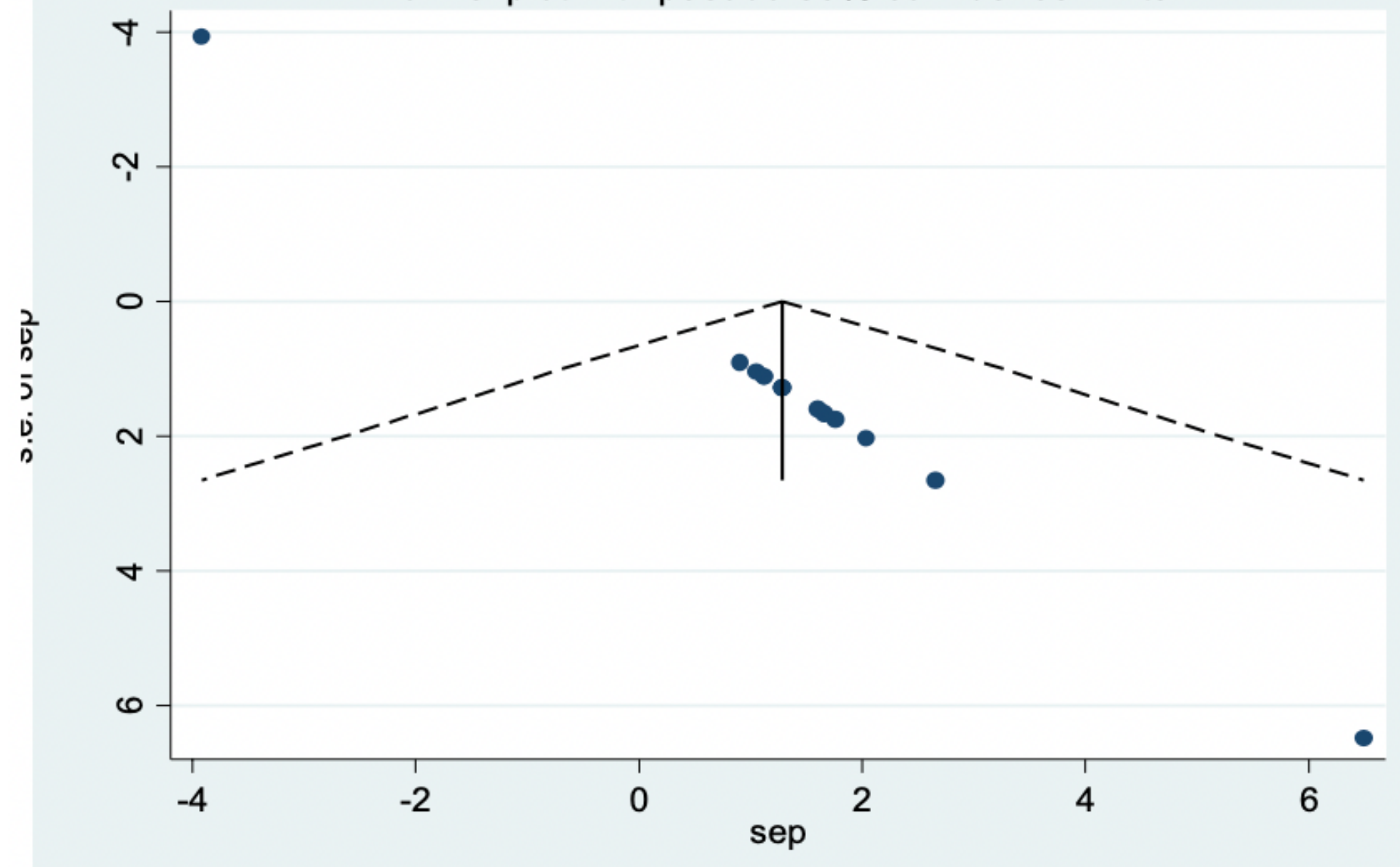

Figure 2

Funnel plot of the included studies 


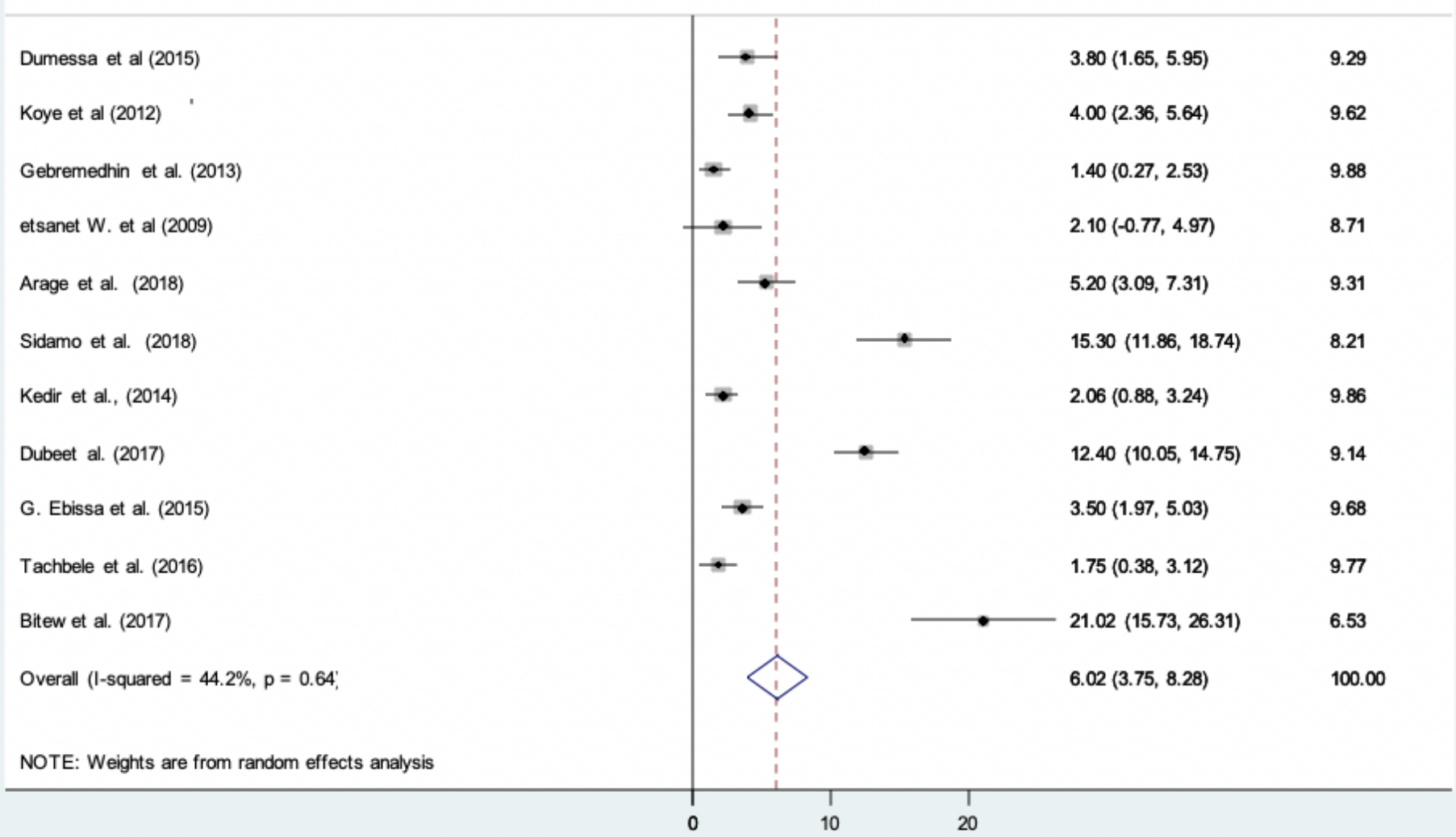

\section{Figure 3}

Incidence of mortality among children on Antiretroviral treatment 
Filled funnel plot with pseudo $95 \%$ confidence limits

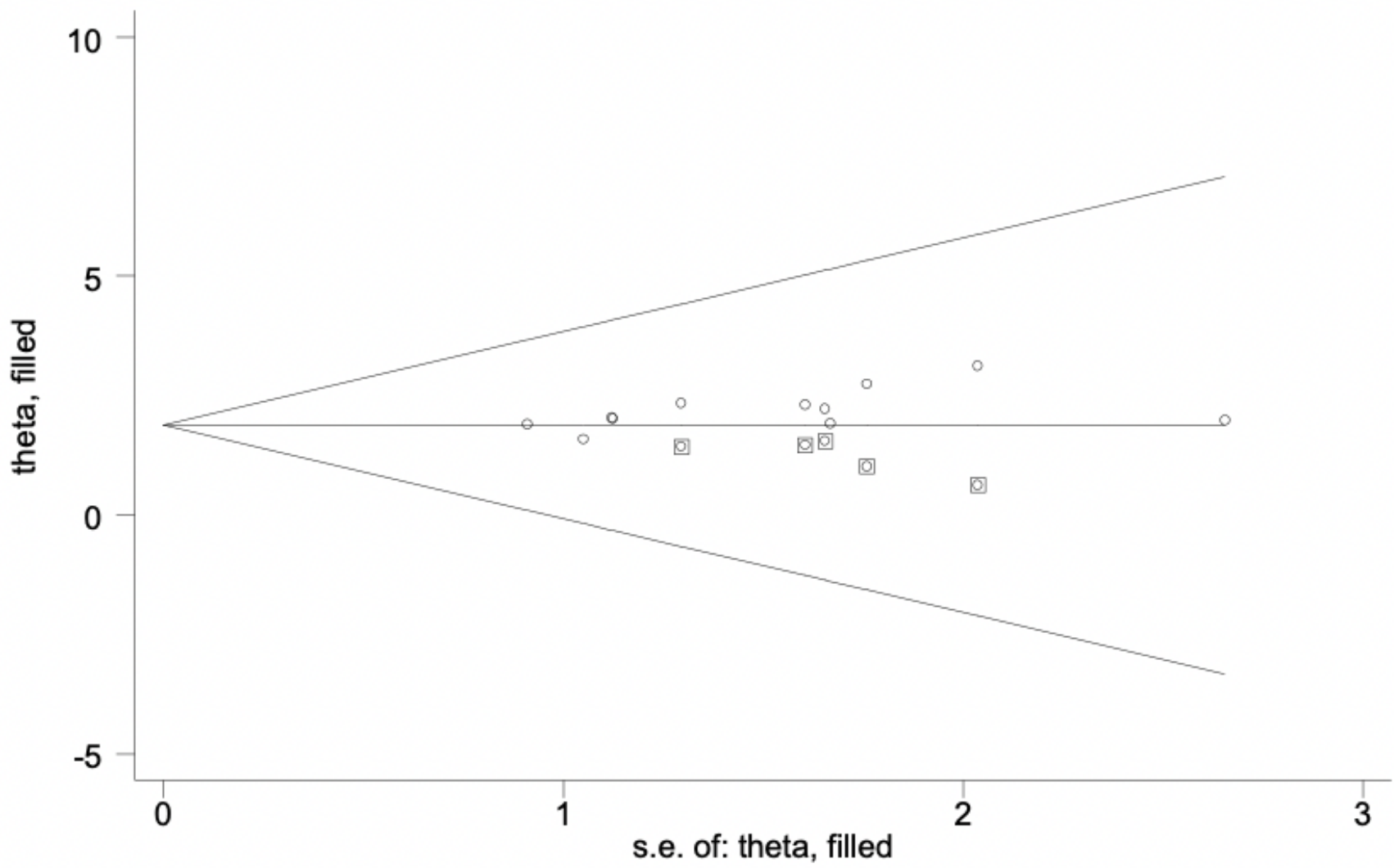

Figure 4

Trim ad fills the analysis results of the included studies. 


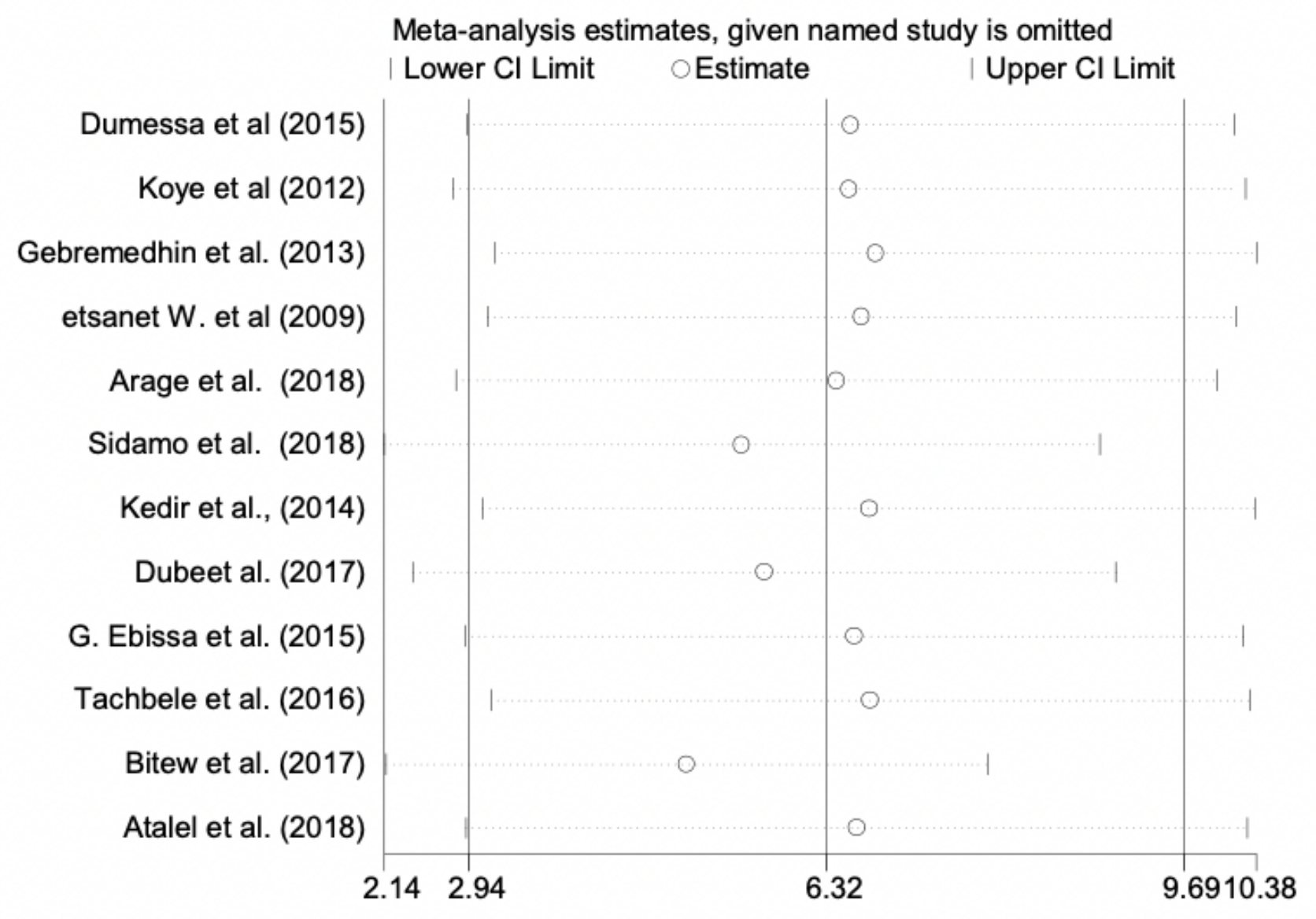

Figure 5

Sensitivity analysis of the included studies. 


\section{Line and Paragraph Spacing}

Authors/year

$\%$

AHR $(95 \% \mathrm{CI}) \quad$ Weight

G. Ebissa et al. (2015)

Dubeet al. (2017)

Sidamo et al. (2014)

Osuorah et al. (2018)

Tachbele et al (2016)

Arage et al. (2018)

Overall $(\mathrm{I}$-squared $=37.5 \%, \mathrm{p}=0.157)$

NOTE: Weights are from random effects analysis

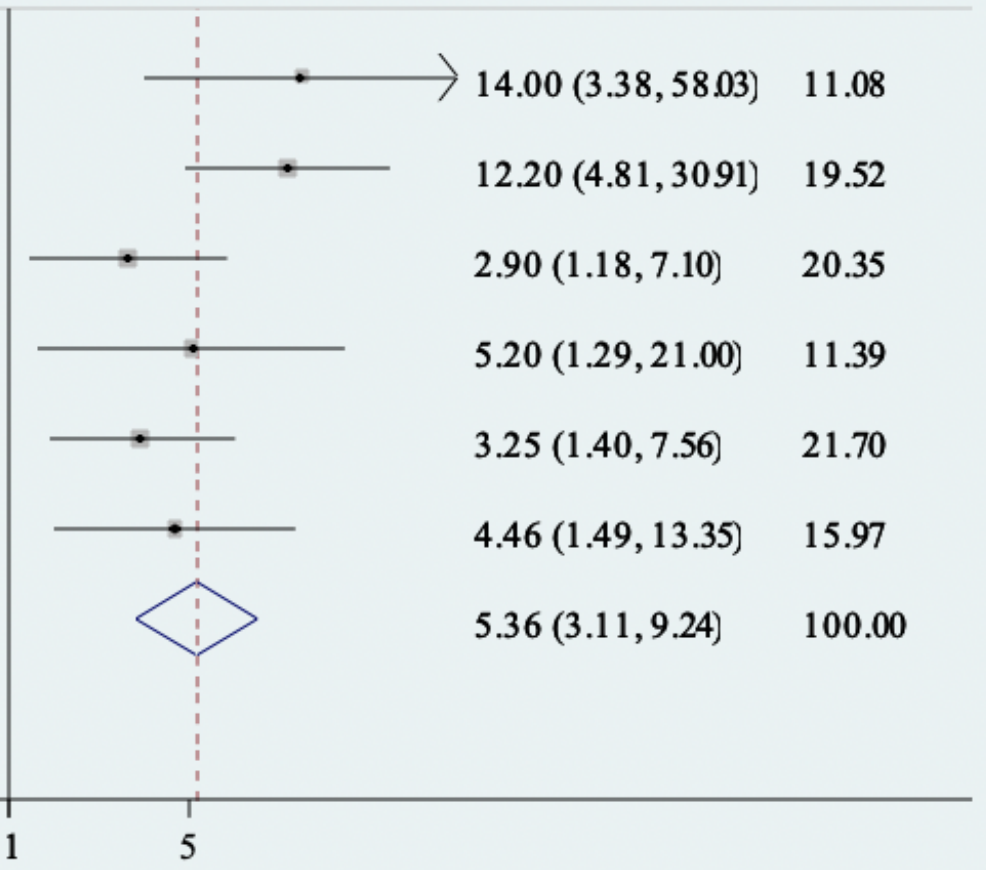

\section{Figure 6}

The association between WHO clinical staging and the incidence of mortality 
Author/yea

$\%$

AHR (95\% CI) Weight

Dubeet al. (2017)

G. Ebissa et al. (2015

Sidamo et al. (2014

Koye et al (2012)

Arage et al. (2018)

Gebremedhin et al. (2013)

Sidamo et al. (2018

Tachbele et al (2016,

Overall (I-squared $=41.9 \%, \mathrm{p}=0.099$ )

NOTE: Weights are from random effects analysis

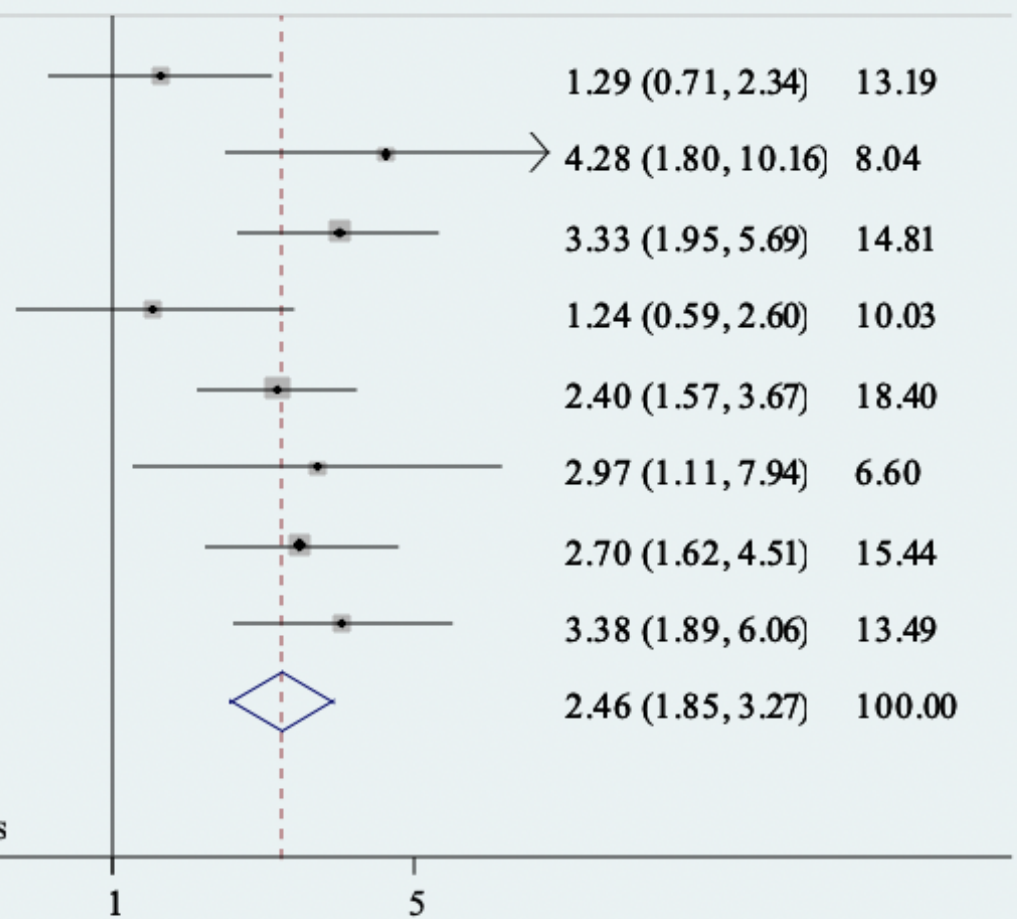

\section{Figure 7}

The association between baseline CD4 Cells count and incidence of mortality 


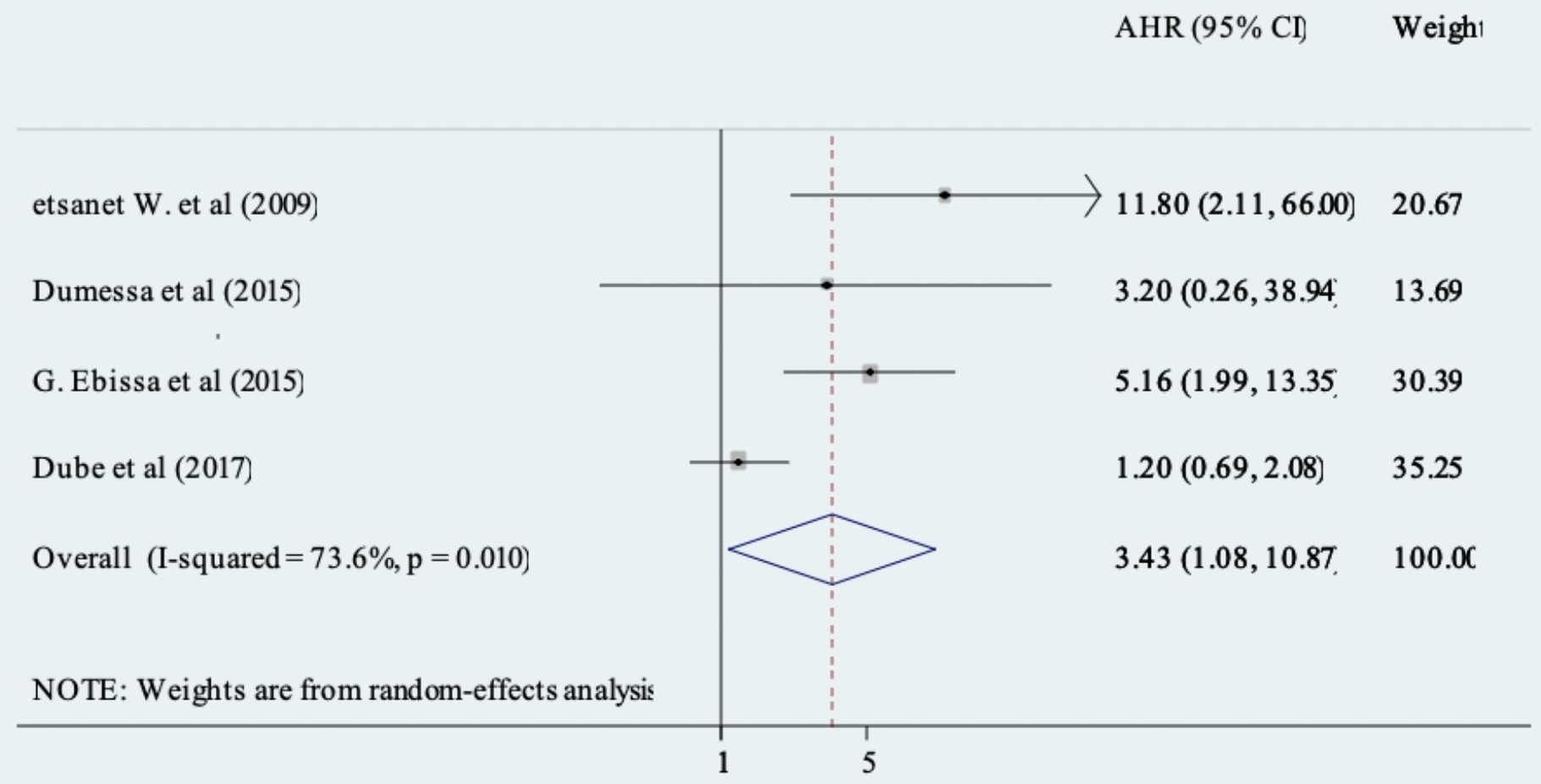

\section{Figure 8}

The association between opportunistic infection and the incidence of mortality 
AHR $(95 \% \mathrm{Cl}) \quad$ Weight

Dubeet al. (2017)

Sidamo et al. (2014)

Sidamo et al. (2014)

Arage et al. (2018)

Overall (I-squared $=0.0 \%, \mathrm{p}=0.732$ )

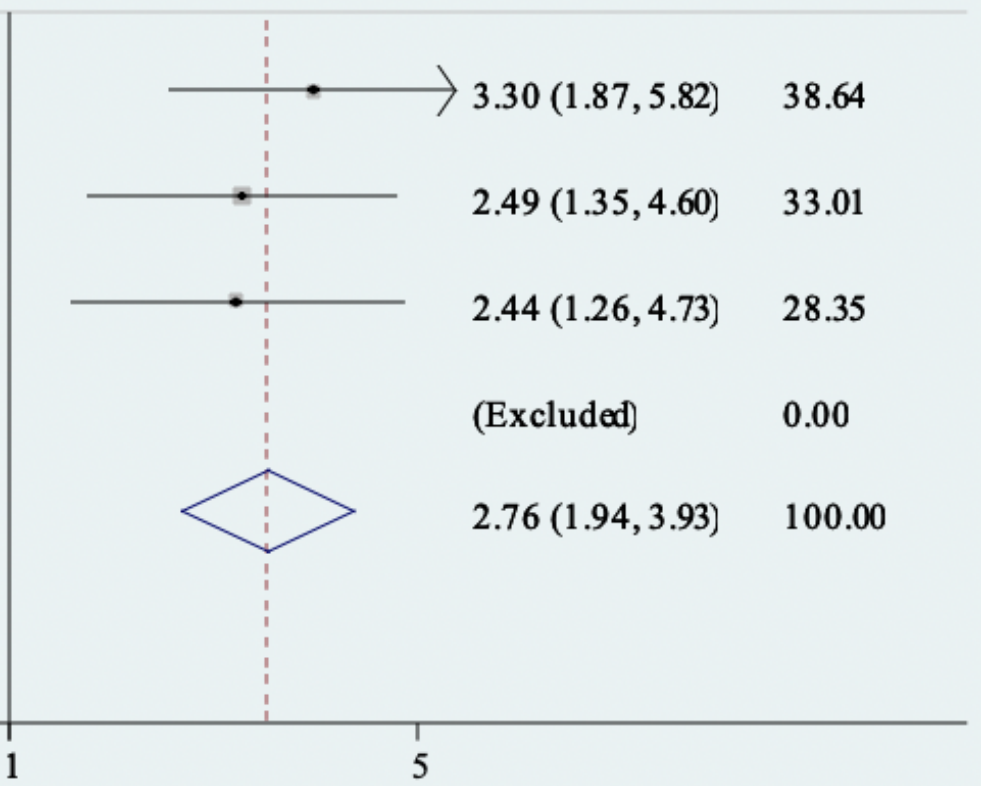

\section{Figure 9}

The association anemia and incidence of mortality 


\section{AHR $(95 \% \mathrm{Cl}) \quad$ Weight}

Sidamo et al. (2014)

Gebremedhin et al. (2013)

Dubeet al. (2017)

Overall (I-squared $=0.0 \%, p=0.653$ )

NOTE: Weights are from random effects analysis

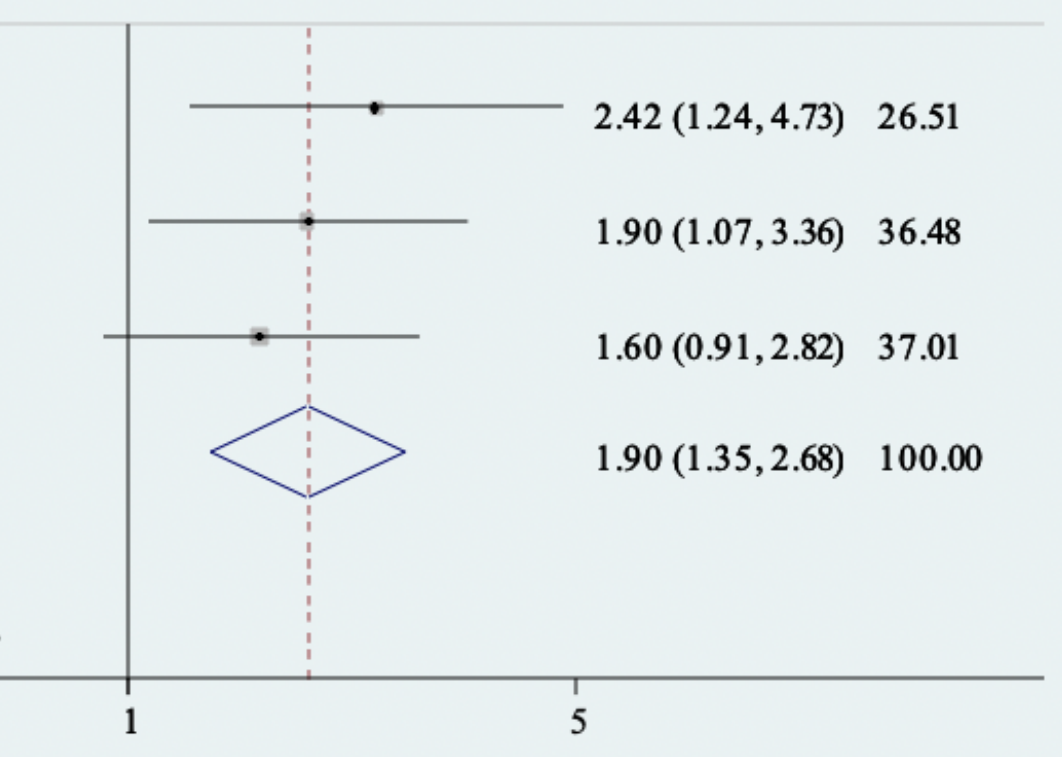

Figure 10

The association nutritional status and incidence of mortality 
AHR $(95 \% \mathrm{CI}) \quad$ Weight

Dubeet al. (2017)

Koye et al (2012)

Arage et al. (2018)

Sidamo et al. (2018)

Gebremedhin et al. (2013)

Overall (I-squared $=86.0 \%, \mathrm{p}=0.000$ )

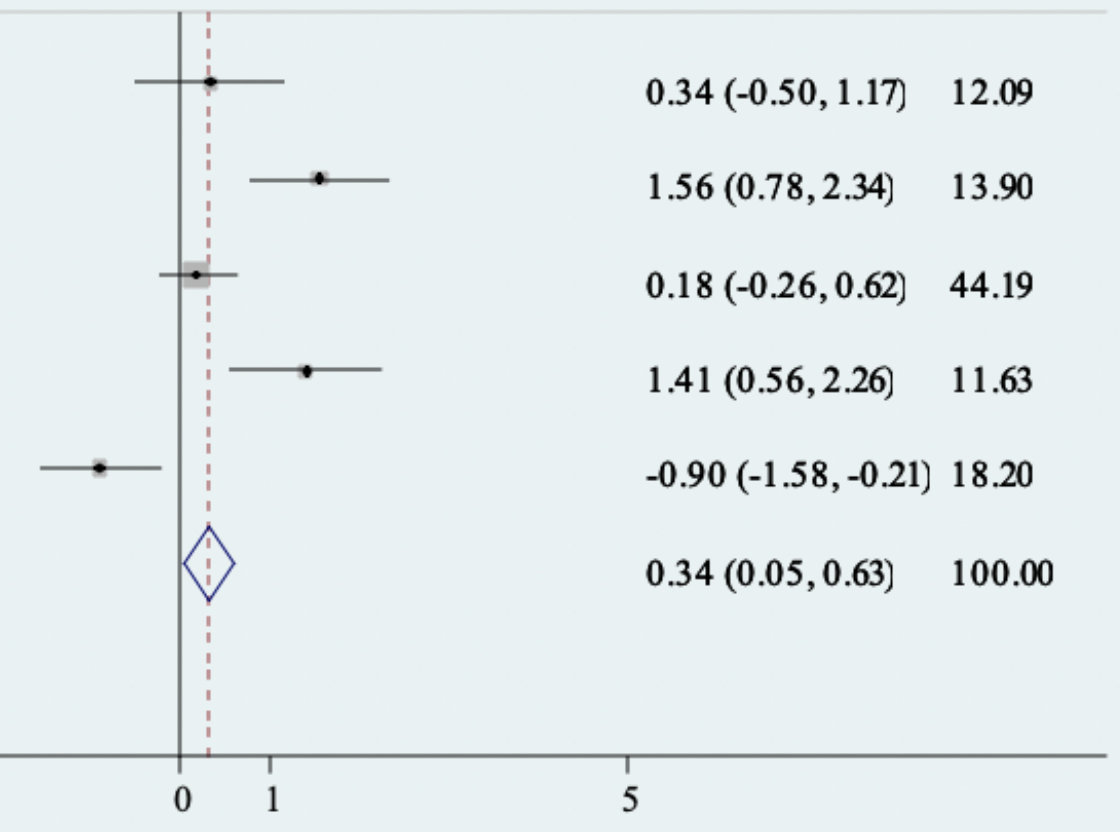

Figure 11

The association CPT and incidence of mortality 